\title{
Validating the HELP Survey to Understand Health Disparity Influence on Chronic Pain
}

\author{
Monika Patel $\mathbb{D}^{\prime}$, Sophia Sheikh², Jennifer Brailsford ${ }^{3}$ \\ 'Department of Anesthesiology, Division of Pain Management, University of Florida College of Medicine, Jacksonville, FL, USA; ${ }^{2}$ Department of \\ Emergency Medicine, University of Florida College of Medicine, Jacksonville, FL, USA; ${ }^{3}$ Center for Data Solutions, University of Florida Health, \\ Jacksonville, FL, USA
}

Correspondence: Monika Patel, Department of Anesthesiology, Division of Pain Management, University of Florida College of Medicine, Pavilion, 2nd Floor, 555 W. 8th street, Jacksonville, FL, 32209, USA, Tel +I 904383 1020, Fax +I 904244 1740, Email monika.patel@jax.ufl.edu

\begin{abstract}
Background: Socioeconomic deprivation is shown to be linked to chronic lower back pain. However, a comprehensive approach to identify key components contributing to pain outcomes using a biopsychosocial model incorporating social determinants of health is needed to develop and tailor successful strategies for mitigating chronic pain development and persistence. We aimed to develop and validate an instrument (the HELP survey) to assess themes characterized by a combination of social determinants of health and the biopsychosocial model in an underserved population. The HELP survey was developed as part of an observational study determining the influence of health disparities on chronic pain interference, The Neighborhood of Pain: Health Disparity Influence on Level of Chronic Pain Interference study (HELP).

Methods: A multidisciplinary group of experts developed the 40-item, 5-domain HELP survey to address Pain Catastrophizing, Pain Motivation, Social Support, Health Care Access, and Physical Environment. After IRB approval, recruitment occurred at an academic pain clinic and emergency department. Survey validation included principal factor analysis, factor loadings of 0.40 or greater, and Cronbach's alpha of 0.70 or greater.

Results: Initial pilot testing occurred in 48 participants, followed by question revision and retesting in 57 patients. The average age was 57 years old. The majority were female (61.9\%), self-reported black (55.2\%), and had a high school health literacy level of $60.9 \%$. Nearly half of participants (52.4\%) lived in a neighborhood of extreme socioeconomic disadvantage and for $43.4 \%$ highest educational attainment was high school. Pilot testing resulted in 5 domains with Cronbach's alphas: Pain Catastrophizing (0.82), Patient Motivation (0.80), Social Support (0.56), Health Care Access (0.75), and Physical Environment (0.81).

Conclusion: Pilot study validation of the HELP survey demographic data indicated testing was performed in an underserved chronic pain population, and questions supported measurement of social determinants of health and the biopsychosocial model based on the five themes identified.
\end{abstract}

Keywords: chronic pain, socioeconomic status, health disparity, survey validation

\section{Background}

Chronic pain has swept the nation, affecting as many as 116 million Americans, leading to long-term disability and massive healthcare costs. ${ }^{1,2}$ It is well known that pain is a multifactorial condition. ${ }^{3}$ Health disparities are preventable differences in the burden of diseases or in the opportunity to achieve optimal health experienced by patients who are socioeconomically disadvantaged. ${ }^{4}$ Health disparities on a global level account for population level differences in health outcomes. Socioeconomic deprivation has been shown to increase biological risk factors for disease, particularly in African Americans. ${ }^{5}$ Socioeconomic deprivation has been linked to chronic lower back pain, however further identification of key components leading to health disparities using a biopsychosocial model and social determinants of health is warranted to develop strategies for improvement of chronic pain development and persistence. ${ }^{6}$ 


\section{Intersection of the Biopsychosocial Pain Model and Social Determinants of Health}

The biopsychosocial pain model highlights the importance of identifying and addressing the psychological and social factors contributing to the development and persistence of pain. ${ }^{3}$ In the $1960 \mathrm{~s}$, the development of a biopsychosocial model helped to delineate the complex interactions of psychological, social, and physiological factors on chronic pain development and persistence. ${ }^{7}$ This model emphasizes that these influences can be different on an individual level and possibly account for individual differences in health care outcomes.

Recently, growing focus has been placed on defining social factors more broadly to groups of people, termed the social determinants of health, in conjunction with the biopsychosocial model on an individual level to better understand how health disparities impact disease outcomes such as functional limitations, morbidity and mortality, health care expenditures, health care utilization, and life expectancy. ${ }^{8}$ The social determinants of health can be broadly classified into economic stability; neighborhood and physical environment; education; food; community and social context; and health care systems. ${ }^{6,8}$ Hardman et al.'s analysis of factors leading to early patient dropout rates from pain self-management treatments at rural Australian pain clinics in areas of high deprivation (defined as low education completion levels, low income, and low employment) showed a significant association of early dropout rate with high levels of pain catastrophizing and literacy deficiencies. ${ }^{9}$ Additional factors contributing to low treatment compliance in areas of high deprivation include young males; history of substance abuse; receiving unemployment benefits; victims of assault; high opioid use and patient conception of pain having a singular cause. ${ }^{9}$ Therefore, better evaluation using components of the biopsychosocial model and social determinants of health may play a critical role in the development and persistence of pain, pain management, and long-term pain outcomes.

\section{Need for a Comprehensive Pain Assessment Tool}

At an individual level, evaluation using the biopsychosocial model along with social determinants of health can be challenging for numerous reasons. No single tool exists. Currently, a proper assessment of important domains would require use of multiple validated surveys which can pose a substantial barrier due to patient reading level, time constraints, survey fatigue and cost of implementing validated surveys. Therefore the HELP survey was created to bridge the gap in evaluation, serving as a single survey assessing patient motivation, health care access, pain catastrophizing, social support, and physical environment. Our objectives were to develop and validate the HELP survey instrument to assess domains characterized by a combination of social determinants of health and the biopsychosocial model in an underserved, urban chronic pain population with degenerative spine conditions. Validation of the HELP survey for this unique patient population will characterize population level differences in factors that influence health care delivery and chronic pain outcomes. It will assist with identification, development, and implementation of targeted interventions to improve health disparity, quality of care and life, and reduce overall healthcare costs in adults with chronic degenerative spine pain.

\section{HELP Survey Development}

As part of the HELP study we proposed a theoretical model of characterizing the biopsychosocial model of pain measurement (Figure 1). The primary evaluation of the pain experience is using factors such as pain intensity, pain limiting function, and pain emotions. The psychosocial factors are secondary in nature that can either negatively or positively impact the pain experience. Finally, clinical evaluation of radiographic spine degeneration and opioid misuse which can also assist in biological pain evaluation. Using this model, the pain, psychosocial, and clinical factors of interest were outlined with Associated Measurement Scales for evaluation (Figure 2). The HELP survey was then derived to measure specific gaps in pain and psychosocial factor evaluation. To ensure a comprehensive assessment of important domains relevant to chronic pain the HELP survey incorporates the domains listed below.

\section{Pain Catastrophizing}

Pain catastrophizing in an exaggerated negative response to a current or anticipated painful stimulus that can lead to increased physical and mental suffering. ${ }^{10}$ The Pain Catastrophizing Scale evaluated themes of rumination, magnification and helplessness in a 13 question, 5 point scale. ${ }^{11}$ However, this scale is lengthy and costly for implementation. Therefore 


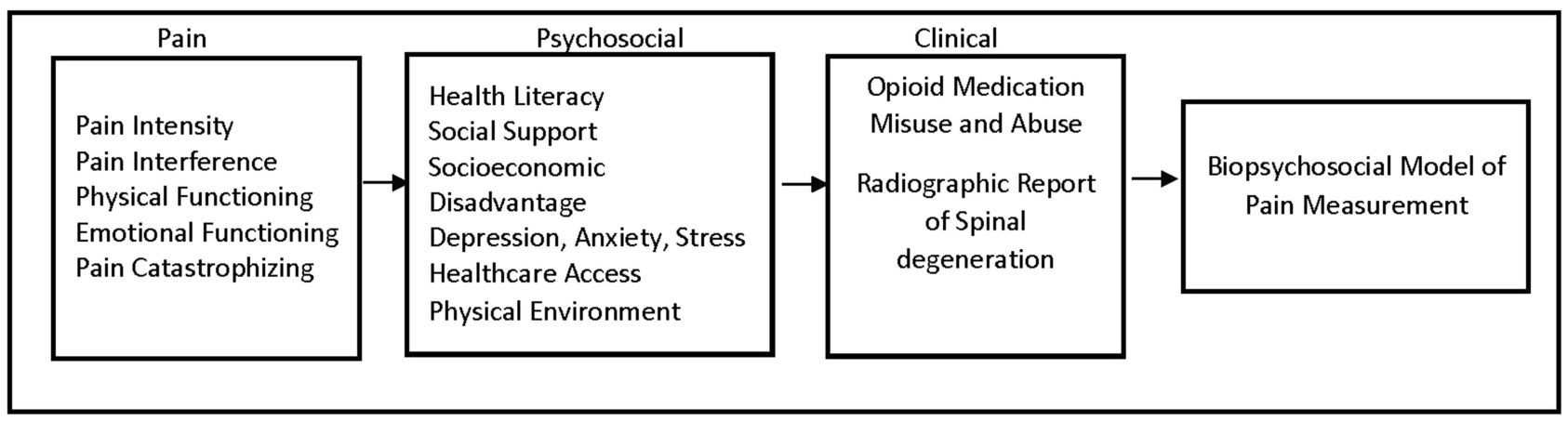

Figure I Theoretical Model.

\begin{tabular}{|c|c|}
\hline \multicolumn{2}{|c|}{ Pain, Psychosocial, and Clinical Factors and Associated Measurement Scales } \\
\hline Factors & Measurement Scale \\
\hline \multicolumn{2}{|l|}{ Pain } \\
\hline $\begin{array}{l}\text { - Pain Intensity } \\
\text { - Pain Interference } \\
\text { - Physical Functioning } \\
\text { - Emotional Functioning } \\
\text { - Pain Catastrophizing }\end{array}$ & $\begin{array}{ll}\text { - } & \text { Patient Reported Outcomes Measurement } \\
\text { Information System (PROMIS) 43v2.1 Profile } \\
\text { - } & \text { HELP Survey (Motivation) } \\
\text { - } & \text { HELP Survey (Pain Catastrophizing) }\end{array}$ \\
\hline \multicolumn{2}{|l|}{ Psychosocial } \\
\hline - Health Literacy & $\begin{array}{l}\text { - Rapid Estimation of Adult Literacy Measure- } \\
\text { Short Form (REALM-SF) }\end{array}$ \\
\hline - Social Support & - $\quad$ HELP Survey (Social Support) \\
\hline - Socioeconomic Disadvantage & - Area of Deprivation Index (ADI) score \\
\hline $\begin{array}{l}\text { Depression, anxiety, and } \\
\text { stress }\end{array}$ & - Depression, Anxiety and Stress Scale (DASS) \\
\hline $\begin{array}{ll} & \text { Perceived barriers to } \\
\text { healthcare access }\end{array}$ & - HELP Survey (Health Care Access) \\
\hline - $\quad$ Physical Environment & - $\quad$ HELP Survey (Physical Environment) \\
\hline \multicolumn{2}{|l|}{ Clinical } \\
\hline $\begin{array}{l}\text { - Opioid medication misuse and } \\
\text { Abuse } \\
\text { - Comorbidity }\end{array}$ & $\begin{array}{ll}\text { - } & \text { PROMIS Short Form v1.0 Prescription } \\
& \text { Medication Misuse Measure } \\
\text { - } & \text { Opioid Risk Tool (ORT) } \\
\text { - } & \text { Functional Comorbidity Index } \\
\text { - } & \text { Smoking History } \\
\text { - } & \text { Body Mass Index (BMI) }\end{array}$ \\
\hline
\end{tabular}

Figure 2 Pain, Psychosocial, and Clinical Factors and Associated Measurement Scales.

the HELP Survey Pain Catastrophizing section was developed using 8 questions on a 5 point Likert scale evaluating pain rumination, pessimism and helplessness.

\section{Pain Motivation}

Patient pain motivation can also influence outcome. ${ }^{12}$ The Patient Activation Measure is a 22 question survey assessing themes of active role, confidence and knowledge, taking action and maintenance. ${ }^{13}$ In the validation process of the Patient Activation Measure, $38 \%$ of the national sample reported to have arthritis as a chronic condition but the survey was not developed to be specific to chronic pain. ${ }^{13}$ Assessment using the Patient Activation Measure, found that those engaged in higher activation had higher self-care, higher health care self-advocacy (seeking care, and understanding of health care condition) and higher sense of control over health. ${ }^{13}$ Implementation of the Patient Activation measure also is costly. ${ }^{13}$ The HELP Survey Pain Motivation section was created using 8 questions evaluating knowledge of pain 
condition, control over pain, pain treatment compliance and long-term lifestyle changes to improve pain using a 5 point Likert scale.

\section{Social Support}

The Multidimensional Scale of Perceived Social Support consists of 12 questions with a 7 point scale geared to identify sources of social support such as significant other, friend, and family. ${ }^{14-16}$ However, the Multidimensional Scale of Perceived Social Support is not specific to chronic pain. Social support is thought to provide resilience to chronic pain conditions. ${ }^{7,12}$ The HELP Survey Social Support section is an 8 question, 5 point Likert scale addressing individual isolation and social support during time of pain.

\section{Health Care Access}

Access to health care may affect chronic pain treatment availability and compliance. The social determinants of health identifies health care system factors including health care coverage and economic stability including expenses and medical bills. ${ }^{8}$ The HELP Survey Health Care Access section identifies health care insurance limitations, medical transportation to appointments, time and expense of seeking pain treatment with 8 questions using a 5 point Likert scale.

\section{Physical Environment}

The social determinants of health also identifies factors related to neighborhood and physical environment such as walkability, safety, transportation, housing and food such as access to healthy food choices. ${ }^{8}$ Medicare recipients in areas of deprivation greater than 85 th percentile reported higher functional limitations. ${ }^{17}$ The HELP Survey Physical Environment section addresses these factors in more detail with 8 questions using a 5 point Likert scale.

\section{Methods}

\section{Study Setting and Recruitment}

The University of Florida Health in Jacksonville, FL (UFH-J) is a large urban safety-net hospital system caring for a predominantly socioeconomically disadvantaged population. The UFH-J serves both the adult and pediatric population with an average patient age of 49, and about half self-report as African American or Hispanic (48\%). Over 466,000 patients receive government or city healthcare assistance and $>13,000$ are self-pay. The UFH-J Pain Management Center treats $>1600$ patients suffering from severe complex chronic pain annually. The majority of these patients are aging adults (73\%), self-reported as African American (41\%), and receive government or city healthcare assistance (88\%). Also the UFH-J Emergency Department recruitment site at the downtown campus is part of a large 700 bed urban safety net hospital with approximately 25,000 inpatient admissions annually. The average ED patient is 50 years old, with $50 \%$ male, $51 \%$ African American, and $25 \%$ on Medicare. The majority of patients live in high Areas of Deprivation with lower levels of education and health literacy. The unique, urban chronic pain population at our institution offers an opportunity to better understand how the social determinants of health and biopsychosocial model influence health disparities in chronic pain outcomes.

This study is part of an IRB approved observational prospective cohort study recruiting patients $\geq 18$ years of age with chronic musculoskeletal pain (pain present for 3 or more months) with radiographic evidence of spine degenerative changes. Patients who are non-English speaking, incarcerated, or unable to provide consent were excluded. All participants who completed the HELP survey were included in the analysis. Recruitment occurred from a large urban safety-net hospital providing care for most of the underserved vulnerable population living in Northeast Florida.

\section{Help Survey Evaluation}

Phase 1: Using the theoretical framework set forth by the Pain Biopsychosocial Model and Social Determinants of Health, HELP survey sections of 8 questions with 5 point Likert scale was developed. These questions were modeled for a 5th grade or less reading level particularly pertaining to pain-related influences. The validated Patient Reported Outcomes Measurement Information System (PROMIS) 43v2.1 Profile was used as a reference. ${ }^{18}$ 
Phase 2: To test initial face-validity, the principal investigator asked a handful of chronic pain patients to read questions and provide informal feedback about the understandability of questions and answer choices during their regular scheduled clinic visits. This small number of patients interviewed found these questions easy to understand.

Phase 3: Pilot-Test Reliability: Next, the survey was pilot tested in patients enrolled in the HELP study. General feedback about patients' understandability of questions was provided by trained research assistants conducting the survey. Reliability of test was analyzed using factor analysis, characterization of domains, and comparison with similar themes present in the validated PROMIS 43v2.1 Profile and Depression, Anxiety and Stress Scale completed at the same time.

Phase 4: Revision-Test- Reliability: Based on results of Phase 3, survey revision was done to improve reliability and validation of survey.

\section{Face and Content Validity}

The HELP survey was developed to build a holistic understanding of chronic pain by utilizing a biopsychosocial model. To build a biopsychosocial model, we assess pain experiences, psychosocial experiences, and clinical factors. A 40 item questionnaire based survey was iteratively developed with content domains as follows: pain catastrophizing; pain motivation; social support; health care access; and physical environment. All questions are answered with a 5 point Likert-scale. Domains were selected after a literature review and subject matter expert review by medical experts in chronic pain management, a nurse practitioner of chronic pain, and an informal patient review.

\section{Pilot Testing}

The survey was pilot tested on a subset of participants from a larger observational prospective cohort study.

\section{Data Analysis \\ Variables Collected}

As part of the HELP study all participants completed the Patient Reported Outcomes Measurement Information System (PROMIS) 43v2.1 Profile, Rapid Estimation of Adult Literacy Measure-Short Form (REALM-SF), Depression, Anxiety and Stress Scale (DASS), PROMIS Short Form v1.0 Prescription Medication Misuse Measure, and Opioid Risk Tool (ORT). Demographic information, medication list, Functional Comorbidity Index, smoking history, Body Mass Index (BMI) and Area of Deprivation Index (ADI) score were collected as well.

Pilot survey data were collected and managed using REDCap ${ }^{25,26}$ electronic data capture tools hosted at the University of Florida, and statistical analysis performed using Stata/IC 16.1. ${ }^{19}$ The state deciles are constructed by ranking the ADI from low to high for each state alone without consideration of national ADIs. Again, group 1 is the lowest ADI (least disadvantaged) and 10 is the highest ADI (most disadvantaged). ${ }^{20}$ The pre-launch analysis included using Principal Component Analysis and Cronbach's Alpha methodology. Initial testing of the survey included extraction of factors using principal component analysis, followed by varimax rotation, to identify independent groups of items.

The determination of the adequacy of the exploratory factor analysis (EFA) was performed through the analysis of Bartlett's test and the Kaiser-Meyer-Olkin (KMO) measure. The KMO statistics range from 0 to 1 , with values closer to 1 denoting greater adequacy of the factor analysis (KMO $\geq 0.6$ low adequacy, $\mathrm{KMO} \geq 0.7$ medium adequacy, $\mathrm{KMO} \geq$ 0.8 high adequacy, $\mathrm{KMO} \geq 0.9$ very high adequacy). If the result of Bartlett's test is $<0.05$, factorial analysis can be used.

For the evaluation of construct validity, the 40 qualitative items of the questionnaire were submitted to the exploratory factor analysis. The questionnaire used Likert scales which uses ordinal variables. Cronbach's alpha was selected as the most appropriate statistical analysis for testing the reliability of grouped questions because it can be used on ordinal data, such as Likert scales. ${ }^{21-24}$ For the purpose of measuring survey reliability using Cronbach's alpha, the survey was organized into five domains: pain catastrophizing, motivation, social support, health care access, and physical environment. Reliability is established by application of internal reliability consistency criteria, e.g., Cronbach's $\alpha 0.70$. Reliability is established for each domain independently. 


\section{Results}

The survey was first piloted in 48 patients. Sociodemographic descriptive statistics are presented for age, race/ethnicity, gender, education, and ADI state decile (Table 1). The HELP survey item and pertaining questions are listed in Table 2. The ability of patients to respond appropriately and comprehensively to the questions supported the instrument's face validity and content validity. The Kaiser-Meyer-Olkin coefficient was 0.77 , and the Bartlett test of sphericity for the 40 item survey was $\mathrm{p}<0.01$, indicating properties of the correlation matrix justified factor analysis carried out. Also, our KMO (0.77) and Bartlett test $(\mathrm{p}<0.01)$ indicated an adequate sample size and moderate inter-correlations indicating EFA is an appropriate statistical analysis for the given data.

Principal factor analysis with a Varimax rotation was used to explore the structure underlying the 40 qualitative items (see Tables 3 and 4). The inclusion or exclusion of an item in a construct was determined iteratively by examining factor loadings and Cronbach's alpha to identify redundant items or items that did not sufficiently measure the same underlying construct. Factor loadings of 0.40 or greater were considered. The first factor included eight items focused on a patient's

Table I Initial HELP Survey Pilot Testing Participant Demographics

\begin{tabular}{|l|l|}
\hline Age (28-79) & $\mathbf{5 8 ( 1 3 . 5 7 )}$ \\
\hline Gender & \\
Male & $20(41.7 \%)$ \\
Female & $28(58.3 \%)$ \\
Race & \\
White & $19(39.6 \%)$ \\
Black & $29(60.4 \%)$ \\
Ethnicity & \\
Hispanic & $1(2.1 \%)$ \\
Non-Hispanic & $47(97.9 \%)$ \\
Education & \\
Less than High School & $10(22.2 \%)$ \\
High School/GED & $19(42.2 \%)$ \\
Some College & $8(17.8 \%)$ \\
College or Above & $8(17.8 \%)$ \\
REALM Score & \\
0-Third Grade and Below & $2(4.5 \%)$ \\
I-3 - Fourth to Sixth Grade & $5(11.4 \%)$ \\
$4-6$ - Seventh to Eighth Grade & $8(18.2 \%)$ \\
7 - High School & $29(65.9 \%)$ \\
ADI State Decile & \\
I & $0(0.0 \%)$ \\
2 & $1(2.1 \%)$ \\
3 & $1(2.1 \%)$ \\
4 & $5(10.6 \%)$ \\
5 & $4(8.5 \%)$ \\
6 & $5(10.6 \%)$ \\
7 & $2(4.3 \%)$ \\
8 & $4(8.5 \%)$ \\
9 & $5(10.6 \%)$ \\
\hline 0 & $20(42.6 \%)$ \\
\hline Notes Descipton of Soci
\end{tabular}

Notes: Description of Socioeconomic Demographics of 48 participants performing initial pilot testing of HELP Survey. Race and Ethnicity are based on participant self-reported data. REALM score is validated measure of Health literacy using the Rapid Estimation of Adult Literacy Measure-Short Form (REALM-SF), ADI stands for Area of Deprivation Index by state decile calculated based on US Census data using participant self-reported address. 
Table 2 Description of Initial Pilot Tested HELP Survey

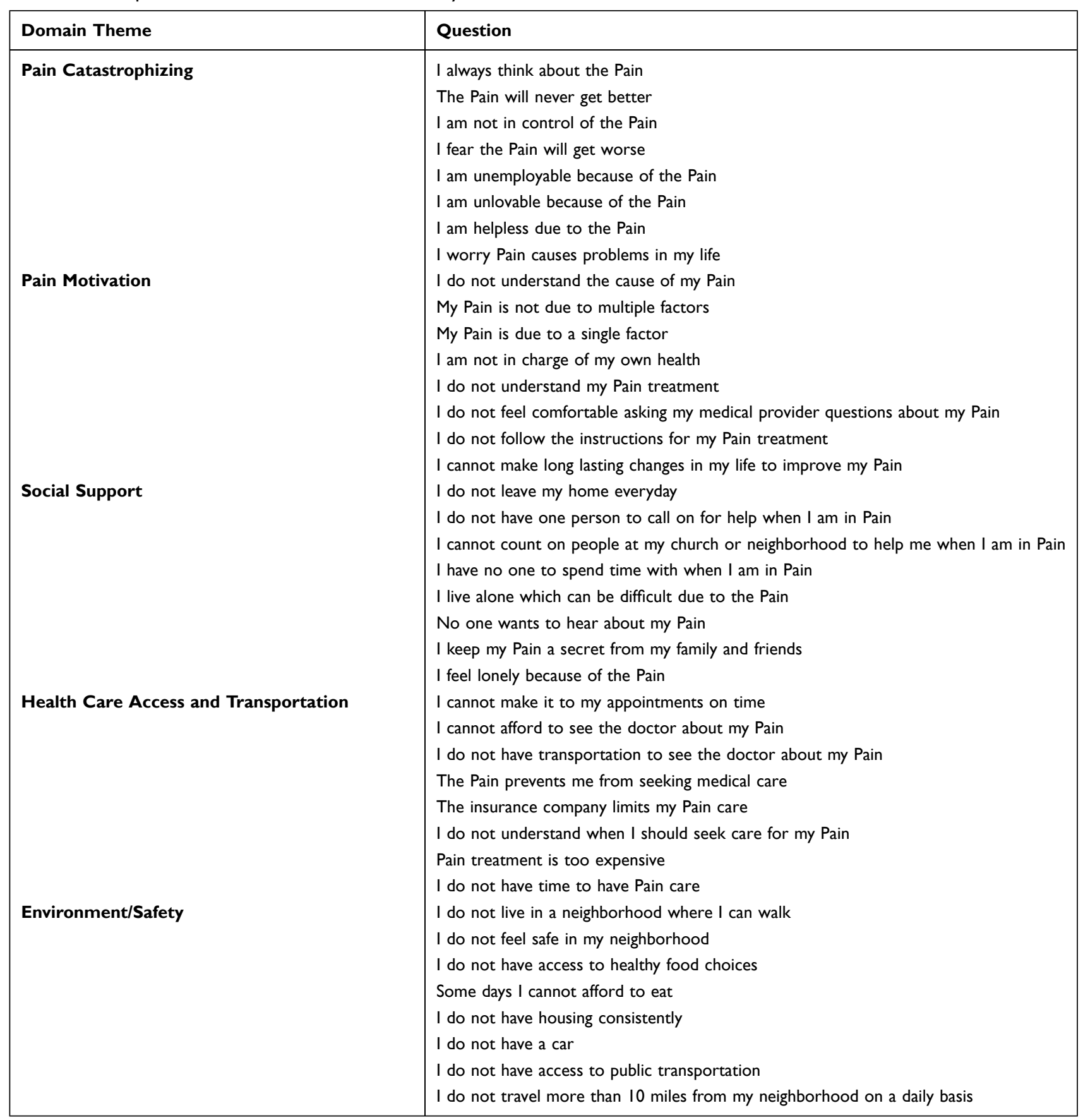

Notes: 40 question using a 5 point Likert scale (Strongly Agree $=$ I, Mildly Agree $=2$, Neutral $=3$, Mildly Disagree $=4$, Strongly Disagree $=5$ ), divided into 5 Domains, 8 questions each.

relationship with pain, including feelings of control and worthiness because of their pain. This factor was labeled as pain catastrophizing. The second factor included eight items related to how patients manage their chronic pain. The third factor consisted of eight items related to social support. The fourth identified factor included eight items related to patient's access to health care. The final factor identified assessed a patient's physical environment with eight items.

Reliability was assessed with Cronbach's alpha (see Table 5). Items with no loading approaching 0.40 factor require consideration for question revision or removal from the revised survey. 
Table 3 Initial Pilot Testing of the HELP Survey with 48 Participants

\begin{tabular}{|c|c|c|c|c|c|}
\hline Variable & Factor I & Factor 2 & Factor 3 & Factor 4 & Factor 5 \\
\hline I always think about the Pain & & 0.3009 & 0.4602 & & 0.5488 \\
\hline The Pain will never get better & & & 0.7705 & -0.5028 & \\
\hline I am not in control of the Pain & -0.3448 & 0.3133 & 0.6521 & & \\
\hline I fear the Pain will get worse & & & 0.888 & & \\
\hline I am unemployable because of the Pain & & 0.6805 & & & \\
\hline I am unlovable because of the Pain & & 0.5556 & 0.348 & & \\
\hline I am helpless due to the Pain & & 0.7785 & & & \\
\hline I worry Pain causes problems in my life & & 0.6102 & 0.3844 & & \\
\hline I do not understand the cause of my Pain & & 0.687 & & 0.3492 & \\
\hline My Pain is not due to multiple factors & 0.4353 & 0.5125 & & & \\
\hline My Pain is due to a single factor & 0.5433 & 0.3847 & & & \\
\hline I am not in charge of my own health & 0.6517 & 0.362 & & & \\
\hline I do not understand my Pain treatment & 0.553 & 0.4429 & & & \\
\hline I do not feel comfortable asking my medical provider questions about my Pain & 0.8887 & & & & \\
\hline I do not follow the instructions for my pain treatment & 0.8083 & & -0.3316 & -0.3514 & \\
\hline I cannot make long lasting changes in my life to improve my Pain & & & 0.6434 & & \\
\hline I do not leave my home everyday & & & 0.393 & & 0.525 \\
\hline I do not have one person to call on for help when I am in Pain & 0.7428 & & & & \\
\hline I cannot count on people at my church or neighborhood to help me when I am in & 0.3354 & & & & \\
\hline Pain & & & & & \\
\hline I have no one to spend time with when I am in Pain & & & 0.3232 & 0.3026 & \\
\hline I live alone which can be difficult due to the Pain & 0.4168 & & & & \\
\hline No one wants to hear about my Pain & & & 0.6543 & & \\
\hline I keep my Pain a secret from my family and friends & & & & & -0.6181 \\
\hline I feel lonely because of the Pain & & 0.5495 & 0.3002 & 0.4343 & \\
\hline I cannot make it to my appointments on time & 0.7095 & & & & \\
\hline I cannot afford to see the doctor about my Pain & 0.518 & & & 0.3179 & \\
\hline I do not have transportation to see the doctor about my Pain & $0.7 I I$ & & & & 0.313 \\
\hline The Pain prevents me from seeking medical care & & 0.3278 & & 0.4454 & \\
\hline The insurance company limits my Pain care & & & & 0.3993 & 0.3516 \\
\hline I do not understand when I should seek care for my Pain & & & & 0.8847 & \\
\hline Pain treatment is too expensive & 0.4456 & 0.4366 & & 0.3615 & \\
\hline I do not have time to have Pain care & $0.7|7|$ & & & & -0.4228 \\
\hline I do not live in a neighborhood where I can walk & 0.688 & & & & \\
\hline I do not feel safe in my neighborhood & 0.4925 & -0.3441 & 0.3646 & & 0.3528 \\
\hline I do not have access to healthy food choices & 0.929 & & & & \\
\hline Some days I cannot afford to eat & 0.3591 & & & & \\
\hline I do not have housing consistently & 0.8634 & & & & \\
\hline I do not have a car & & 0.5265 & & & 0.4511 \\
\hline I do not have access to public transportation & 0.8406 & & & & \\
\hline I do not travel more than 10 miles from my neighborhood on a daily basis & & & & & 0.7156 \\
\hline
\end{tabular}

Notes: Use the loading plot to identify which variables have the largest effect on each component. Loadings can range from $-I$ to I. Loadings close to $-I$ or I indicate that the variable strongly influences the component. Loadings close to 0 indicate that the variable has a weak influence on the component. Positive loadings indicate a variable and a principal component are positively correlated: an increase in one results in an increase in the other. Blank spaces represent abs(loading)<.3. Principal Component Factor Analysis is limited at this stage due to low number of participants with high number of questions.

\section{Revision and Retest of Survey}

Next, based on the results of the initial pilot testing of 48 participants, and research assistant feedback regarding which questions participants asked for clarification during the study, questions were revised. Majority of revisions were made to questions that were worded using double negative sentences. These questions were rephrased as positive statements with 
Table 4 Factor Analysis of Initial Pilot Test of HELP Survey with 48 Participants

\begin{tabular}{|c|c|c|}
\hline Factors & Items & $\begin{array}{l}\text { Factor } \\
\text { Loading }\end{array}$ \\
\hline Pain Catastrophizing & $\begin{array}{l}\text { I always think about the Pain } \\
\text { The Pain will never get better } \\
\text { I am not in control of the Pain } \\
\text { I fear the Pain will get worse } \\
\text { I am unemployable because of the Pain } \\
\text { I am unlovable because of the Pain } \\
\text { I am helpless due to the Pain } \\
\text { I worry Pain causes problems in my life }\end{array}$ & $\begin{array}{l}0.62 \\
0.66 \\
0.64 \\
0.67 \\
0.60 \\
0.62 \\
0.71 \\
0.67\end{array}$ \\
\hline Pain Motivation & $\begin{array}{l}\text { I do not understand the cause of my Pain } \\
\text { My Pain is not due to multiple factors } \\
\text { My Pain is due to a single factor } \\
\text { I am not in charge of my own health } \\
\text { I do not understand my Pain treatment } \\
\text { I do not feel comfortable asking my medical provider questions about my Pain } \\
\text { I do not follow the instructions for my Pain treatment } \\
\text { I cannot make long lasting changes in my life to improve my Pain }\end{array}$ & $\begin{array}{l}0.55 \\
0.57 \\
0.63 \\
0.85 \\
0.86 \\
0.80 \\
0.63 \\
0.25\end{array}$ \\
\hline Social Support & $\begin{array}{l}\text { I do not leave my home everyday } \\
\text { I do not have one person to call on for help when I am in Pain } \\
\text { I cannot count on people at my church or neighborhood to help me when } \\
\text { I am in Pain } \\
\text { I have no one to spend time with when I am in Pain } \\
\text { I live alone which can be difficult due to the Pain } \\
\text { No one wants to hear about my Pain } \\
\text { I keep my Pain a secret from my family and friends } \\
\text { I feel lonely because of the Pain }\end{array}$ & $\begin{array}{l}0.56 \\
0.71 \\
0.37 \\
0.72 \\
0.55 \\
0.73 \\
0.42 \\
0.60\end{array}$ \\
\hline Health Care Access and Transportation & $\begin{array}{l}\text { I cannot make it to my appointments on time } \\
\text { I cannot afford to see the doctor about my Pain } \\
\text { I do not have transportation to see the doctor about my Pain } \\
\text { The Pain prevents me from seeking medical care } \\
\text { The insurance company limits my Pain care } \\
\text { I do not understand when I should seek care for my Pain } \\
\text { Pain treatment is too expensive } \\
\text { I do not have time to have Pain care }\end{array}$ & $\begin{array}{l}0.66 \\
0.78 \\
0.73 \\
0.84 \\
0.31 \\
0.67 \\
0.42 \\
0.48\end{array}$ \\
\hline Environment/Safety & $\begin{array}{l}\text { I do not live in a neighborhood where I can walk } \\
\text { I do not feel safe in my neighborhood } \\
\text { I do not have access to healthy food choices } \\
\text { Some days I cannot afford to eat } \\
\text { I do not have housing consistently } \\
\text { I do not have a car } \\
\text { I do not have access to public transportation } \\
\text { I do not travel more than } 10 \text { miles from my neighborhood on a daily basis }\end{array}$ & $\begin{array}{l}0.65 \\
0.63 \\
0.80 \\
0.57 \\
0.62 \\
0.34 \\
0.38 \\
0.06\end{array}$ \\
\hline
\end{tabular}

a reversal of the Likert scoring scale (see Table 6 for HELP Survey question revisions listed in italics font with corresponding reverse scoring).

The revised survey was tested on an additional 57 participants as part of continued HELP study enrollment. All revised HELP surveys completed were analyzed and no survey results were excluded. To increase sample size of analysis, the initial 48 patient survey results were included with the 57 participants surveyed with the revised scale and 
Table 5 Reliability of the Initial Pilots Testing of HELP Survey with 48 Participants

\begin{tabular}{|l|l|}
\hline Scale & Cronbach's Alpha \\
\hline Pain Catastrophizing & 0.86 \\
Pain Motivation & 0.83 \\
Social Support & 0.77 \\
Health Care Access and Transportation & 0.80 \\
Physical Environment & 0.80 \\
\hline
\end{tabular}

reverse scoring. The merger of the two samples was justified because the question revisions were minor changes from negative to positive statements for respondents' improved understanding without major changes to question subject, tone, reading level, or Likert scale. Again, the statistical analysis was performed in the same manner as before. Results are outlined in Tables 7-10. Increased sample size with addition of survey question revisions showed the trend towards improved validation.

\section{Discussion}

This process of validating the HELP survey was performed due to the need for a cost-effective and easily administrable comprehensive biopsychosocial evaluation of pain with the goal of improving pain management outcomes. The 5 HELP survey domains were considered relevant to chronic pain outcomes specifically based on literature review and multidisciplinary pain provider expert input.

\section{Pain Catastrophizing}

The HELP Survey Pain Catastrophizing section was developed using 8 questions on a 5 point Likert scale evaluating pain rumination, pessimism and helplessness. This section did not need question revision, as respondents easily understood the phrases related to the targeted subject. The Cronbach's alpha score of 0.82 also verified the reliability and fit of these questions into the Pain Catastrophizing domain.

\section{Pain Motivation}

There was no existing survey evaluating Pain Motivation developed for evaluation focused on chronic musculoskeletal or spinal degenerative pain. Therefore, the HELP Survey Pain Motivation section was created using 8 questions evaluating knowledge of pain condition, control over pain, pain treatment compliance and long-term lifestyle changes to improve pain using a 5 point Likert scale. Initial piloting of these questions showed respondents had difficulty in understanding questions due to double negative phrases. So phrases were reworded to positive statements with reverse score answers. Also, the question "My pain is from a single factor" was removed after pilot testing because respondents felt it was a similar inverse of the previous question "My pain is due to multiple factors" leaving room for internal respondent conflicting answers. Retesting of the revised questions did slightly decrease the Cronbach's alpha from 0.83 to 0.80 , and only seven questions remaining in this domain. However, this result still showed reliability of these questions within the Pain Motivation domain.

\section{Social Support}

Strong social support is thought to provide improved chronic pain outcomes, but evaluation of individual social support structure can be difficult. ${ }^{7,12}$ The HELP Survey Social Support section is an 8 question, 5 point Likert scale addressing individual isolation and social support during time of pain. These eight questions aim to assess social support from an individual level of assessment of loneliness, to integration in social activities, to community support. Three of these questions were rephrased from negative statements to positive phrases based on initial pilot testing. However, subsequent testing of revised questions decreased the Cronbach's alpha from 0.77 to 0.56 , showing the revised questions did not 
Table 6 Revised HELP Survey

\begin{tabular}{|c|c|}
\hline Domain Theme & Question \\
\hline Pain Catastrophizing & $\begin{array}{l}\text { I always think about the Pain } \\
\text { The Pain will never get better } \\
\text { I am not in control of the Pain } \\
\text { I fear the Pain will get worse } \\
\text { I am unemployable because of the Pain } \\
\text { I am unlovable because of the Pain } \\
\text { I am helpless due to the Pain } \\
\text { I worry Pain causes problems in my life }\end{array}$ \\
\hline Pain Motivation & $\begin{array}{l}\text { Reverse score I understand the cause of my Pain } \\
\text { Reverse score My Pain is due to multiple factors } \\
\text { Removed Question: My Pain is due to a single factor } \\
\text { Reverse score I am in charge of my own health } \\
\text { Reverse score I understand my Pain treatment } \\
\text { Reverse score I feel comfortable asking my medical provider questions about my Pain } \\
\text { Reverse score I do follow the instructions for my pain treatment } \\
\text { Reverse score I can make long lasting changes in my life to improve my Pain }\end{array}$ \\
\hline Social Support & $\begin{array}{l}\text { Reverse score I leave my home everyday } \\
\text { Reverse score I have one person to call on for help when I am in Pain } \\
\text { Reverse score I can count on people at my church or neighborhood to help me when I am in Pain } \\
\text { I have no one to spend time with when I am in Pain } \\
\text { I live alone which can be difficult due to the Pain } \\
\text { No one wants to hear about my Pain } \\
\text { I keep my Pain a secret from my family and friends } \\
\text { I feel lonely because of the Pain }\end{array}$ \\
\hline Health Care Access and & Reverse score I can make it to my appointments on time \\
\hline Transportation & $\begin{array}{l}\text { Reverse score I can afford to see the doctor about my pain } \\
\text { Reverse score I have transportation to see the doctor about my Pain } \\
\text { Reverse score I understand when I should seek care for my Pain } \\
\text { The Pain prevents me from seeking medical care } \\
\text { The insurance company limits my Pain care } \\
\text { Reverse score I understand when I should seek care for my Pain } \\
\text { Pain treatment is too expensive } \\
\text { Reverse score I have time to have Pain care } \\
\text { Reverse score I live in a neighborhood where I can walk }\end{array}$ \\
\hline Environment/Safety & $\begin{array}{l}\text { Reverse score I feel safe in my neighborhood } \\
\text { Reverse score I have access to healthy food choices } \\
\text { Some days I cannot afford to eat } \\
\text { Reverse score I have housing consistently } \\
\text { Reverse score I have a car } \\
\text { Reverse score I have access to public transportation } \\
\text { Reverse score I travel more than I0 miles from my neighborhood on a daily basis }\end{array}$ \\
\hline
\end{tabular}

Notes: 39 question using a 5 point Likert scale (Strongly Agree = I, Mildly Agree = 2, Neutral = 3, Mildly Disagree $=4$, Strongly Disagree $=5$ ), and Reverse Scoring of positive statements (Strongly Agree = 5, Mildly Agree = 4, Neutral = 3, Mildly Disagree = 2, Strongly Disagree $=1$ ) divided into 5 Domains, 8 questions each, except Pain Motivation which is 7 questions. Revised questions listed in italics font.

reach clarity and fit into the Social Support domain. Further, revision of these questions is warranted with the goal of the section reliably evaluating social support from an individual to societal level specifically for chronic pain conditions.

\section{Health Care Access}

Access to health care, health care coverage and financial stability may all influence pan outcomes. ${ }^{8}$ The HELP Survey Health Care Access section identifies health care insurance limitations, medical transportation to appointments, time and 
Table 7 Description of Socioeconomic Demographics of 105 Participants

\begin{tabular}{|l|l|}
\hline Age (28-8I) & $\mathbf{5 7 ( 9 . 9 1 )}$ \\
\hline Gender & \\
Male & $40(38.10 \%)$ \\
Female & $65(61.90 \%)$ \\
Race & \\
White & $46(43.81 \%)$ \\
Black & $58(55.24 \%)$ \\
Other & $1(0.95 \%)$ \\
Ethnicity & \\
Hispanic & $3(2.86 \%)$ \\
Non-Hispanic & $102(97.14 \%)$ \\
Education & \\
Less than High School & $16(16.16 \%)$ \\
High School Diploma/GED & $43(43.43 \%)$ \\
Some College & $24(24.24 \%)$ \\
College and Above & $16(16.16 \%)$ \\
REALM Score & \\
0 - Third Grade and Below & $3(2.94 \%)$ \\
I-3 - Fourth to Sixth Grade & $10(9.80 \%)$ \\
$4-6$ - Seventh to Eighth Grade & $27(26.47 \%)$ \\
7 - High School & $62(60.78 \%)$ \\
ADI State Decile & \\
I & $1(0.97 \%)$ \\
2 & $3(2.91 \%)$ \\
3 & $4(3.88 \%)$ \\
4 & $8(7.77 \%)$ \\
5 & $8(7.77 \%)$ \\
6 & $9(8.74 \%)$ \\
7 & $6(5.83 \%)$ \\
8 & $10(9.71 \%)$ \\
9 & $14(13.59 \%)$ \\
\hline 0 & $40(38.83 \%)$ \\
\hline Not & \\
\hline
\end{tabular}

Notes: Forty-eight participants from initial pilot testing of HELP survey and additional 57 participants from pilot testing of Revised HELP Survey. Race and Ethnicity are based on participant selfreported data. REALM score is validated measure of Health literacy using the Rapid Estimation of Adult Literacy Measure- Short Form (REALM-SF), ADI stands for Area of Deprivation Index by state decile calculated based on US Census data using participant self-reported address.

expense of seeking pain treatment with 8 questions using a 5 point Likert scale. After initial testing, five questions were rephrased to positive statements with reverse scoring. The subsequent testing revealed a Cronbach's alpha of 0.75 showing reliability of these questions in the Health Care Access domain.

\section{Physical Environment}

Neighborhood deprivation and physical environment such as walkability, safety and healthy food choices can affect health outcomes. ${ }^{8,17}$ The HELP Survey Physical Environment section addresses key factors thought to contribute to pain outcomes with 8 questions using a 5 point Likert scale. All 8 questions were changed to positive statements with reverse scoring after initial testing. The subsequent testing revealed a Cronbach's alpha of 0.81 showing reliability of these questions in the Physical Environment domain. 
Table 8 Principal Component Analysis for Revised HELP Survey

\begin{tabular}{|c|c|c|c|c|c|}
\hline Variable & Factor I & Factor 2 & Factor 3 & Factor 4 & Factor 5 \\
\hline I always think about the Pain & & 0.4254 & & -0.2348 & \\
\hline The Pain will never get better & & 0.46 & & & \\
\hline I am not in control of the Pain & & 0.3917 & & & \\
\hline I fear the Pain will get worse & & 0.2397 & & & \\
\hline I am unemployable because of the Pain & & & & & \\
\hline I am unlovable because of the Pain & & 0.2049 & & & \\
\hline I am helpless due to the Pain & & 0.374 & & & \\
\hline I worry Pain causes problems in my life & & 0.2986 & & & \\
\hline I understand the cause of my Pain & & & & & \\
\hline My Pain is due to multiple factors & -0.2389 & & & & \\
\hline I am in charge of my own health & -0.2321 & & & & \\
\hline I understand my Pain treatment & -0.2351 & & & & \\
\hline I feel comfortable asking my medical provider questions about my Pain & & & -0.4052 & & \\
\hline I do follow the instructions for my Pain treatment & 0.2818 & & & & \\
\hline I can make long lasting changes in my life to improve my Pain & & & & & \\
\hline I leave my home every day & & & & & 0.5226 \\
\hline I have one person to call on for help when I am in Pain & & & & & 0.284 \\
\hline I can count on people at my church or neighborhood to help me when I am in Pain & & & & & 0.3407 \\
\hline I have no one to spend time with when I am in Pain & & & & & \\
\hline I live alone which can be difficult due to the Pain & & & 0.4465 & -0.2489 & \\
\hline No one wants to hear about my Pain & & & 0.3503 & & \\
\hline I keep my Pain a secret from my family and friends & & & 0.3793 & & \\
\hline I feel lonely because of the Pain & & & 0.3136 & & \\
\hline I can make it to my appointments on time & 0.2563 & & & & \\
\hline I can afford to see the doctor about my Pain & 0.2539 & & & & \\
\hline I have transportation to see the doctor about my Pain & 0.2604 & & & & \\
\hline The Pain prevents me from seeking medical care & & & & 0.4421 & \\
\hline The insurance company limits my Pain care & & & & 0.573 & -0.2558 \\
\hline I understand when I should seek care for my Pain & & & & 0.4486 & \\
\hline Pain treatment is too expensive & 0.2246 & & & & \\
\hline I have time to have Pain care & 0.2452 & & & & \\
\hline I live in a neighborhood where I can walk & & & & & \\
\hline I feel safe in my neighborhood & & & & & \\
\hline I have access to healthy food choices & 0.2694 & & & & \\
\hline Some days I cannot afford to eat & 0.2729 & & 0.2114 & & \\
\hline I have housing consistently & 0.2957 & & & & \\
\hline I have a car & & & & & 0.2009 \\
\hline I have access to public transportation & 0.2325 & & & & \\
\hline I travel more than 10 miles from my neighborhood on a daily basis & & & & & 0.495 \\
\hline
\end{tabular}

Notes: The Prinicipal Component Analysis was performed and loading plot identified which variables have the strongest influence on the component (closer to $-\mathrm{I}$ or I) or weak influence (closer to 0 ). The overall purpose of a PCA analysis is to reduce variables by understanding which variables explain the most variance in each factor. $94 \%$ of the variance was explained by the first 29 variables. Revised questions listed in italics font.

\section{Conclusions}

From the literature review, it was concluded there were several gaps in the study of pain. Although there are several validated measures for measuring pain, this is the first survey to combine aspects of the social determinants of health and mental health to create a biopsychosocial model of pain measurement in an underserved chronic pain population. This paper explains the preliminary development of a new instrument to fill these gaps in chronic pain patient evaluation. The importance of these preliminary validation results mostly aligned with the themes of interest based on literature review of importance for the biopsychosocial model of pain when tested in this disadvantaged subpopulation within the chronic pain population. 
Table 9 Factor Analysis of Revised HELP Survey

\begin{tabular}{|c|c|c|}
\hline Factors & Items & $\begin{array}{l}\text { Factor } \\
\text { Loading }\end{array}$ \\
\hline \multirow[t]{8}{*}{ Pain Catastrophizing } & I always think about the Pain & 0.81 \\
\hline & The Pain will never get better & 0.79 \\
\hline & I am not in control of the Pain & 0.80 \\
\hline & I fear the Pain will get worse & 0.80 \\
\hline & I am unemployable because of the Pain & 0.81 \\
\hline & I am unlovable because of the Pain & 0.82 \\
\hline & I am helpless due to the Pain & 0.80 \\
\hline & I worry Pain causes problems in my life & 0.78 \\
\hline \multirow[t]{7}{*}{ Pain Motivation } & I understand the cause of my Pain & 0.76 \\
\hline & My Pain is due to multiple factors & 0.75 \\
\hline & I am in charge of my own health & 0.73 \\
\hline & I understand my Pain treatment & 0.74 \\
\hline & I feel comfortable asking my medical provider questions about my Pain & 0.85 \\
\hline & I follow the instructions for my Pain treatment & 0.74 \\
\hline & I can make long lasting changes in my life to improve my Pain & 0.80 \\
\hline \multirow[t]{8}{*}{ Social Support } & I leave my home everyday & 0.59 \\
\hline & I have one person to call on for help when I am in Pain & 0.58 \\
\hline & I can count on people at my church or neighborhood to help me when I am in Pain & 0.63 \\
\hline & I have no one to spend time with when I am in Pain & 0.47 \\
\hline & I live alone which can be difficult due to the Pain & 0.49 \\
\hline & No one wants to hear about my Pain & 0.46 \\
\hline & I keep my Pain a secret from my family and friends & 0.49 \\
\hline & I feel lonely because of the Pain & 0.45 \\
\hline \multirow[t]{8}{*}{ Health Care Access and Transportation } & I can make it to my appointments on time & 0.68 \\
\hline & I can afford to see the doctor about my Pain & 0.69 \\
\hline & I have transportation to see the doctor about my Pain & 0.68 \\
\hline & The Pain prevents me from seeking medical care & 0.76 \\
\hline & The insurance company limits my Pain care & 0.77 \\
\hline & I understand when I should seek care for my Pain & 0.77 \\
\hline & Pain treatment is too expensive & 0.70 \\
\hline & I have time to have Pain care & 0.69 \\
\hline \multirow[t]{8}{*}{ Environment/Safety } & I live in a neighborhood where I can walk & 0.77 \\
\hline & I feel safe in my neighborhood & 0.78 \\
\hline & I have access to healthy food choices & 0.76 \\
\hline & Some days I cannot afford to eat & 0.77 \\
\hline & I have housing consistently & 0.75 \\
\hline & I have a car & 0.83 \\
\hline & I have access to public transportation & 0.78 \\
\hline & I travel more than 10 miles from my neighborhood on a daily basis & 0.86 \\
\hline \multicolumn{2}{|l|}{ Total Scale } & 0.90 \\
\hline
\end{tabular}

Note: Revised questions listed in italics font.

\section{Limitations}

The work described in this paper is in the preliminary stage of survey validation. This study has several limitations, the main one being the current sample size. Despite the small sample size, the results of PCA and factor analysis are promising for further validation of the survey. While the sample size for initial validation is limited, this pilot survey 
Table 10 Reliability of the Revised HELP Survey

\begin{tabular}{|l|l|}
\hline Scale & Cronbach's Alpha \\
\hline Pain Catastrophizing & 0.82 \\
Pain Motivation & 0.80 \\
Social Support & 0.56 \\
Health Care Access and Transportation & 0.75 \\
Physical Environment & 0.81 \\
\hline
\end{tabular}

implementation provides insight into the evaluation of selected factors from the biopsychosocial model and social determinants of health in an urban chronic pain population. Additionally, the recruitment of disadvantaged populations such as minority participants, high level of deprivation, and chronic pain may pose challenges limiting sample size. The HELP survey validation study also had a small sample size because enrollment was linked to the HELP study enrollment and funding. However, future funding and enrollment will be obtained to specifically focus on validating the HELP survey as an independent study to increase funding allocation for larger sample size recruitment.

\section{Future}

Based on the preliminary survey validation, rewording of certain questions is needed for clarity and fit within the Social Support Domain because of the Cronbach's Alpha being below the target 0.70 . Additionally, a question within the Pain Motivation can be added to replace the question removed to have a full 8 question assessment. However, the scope of this initial HELP survey pilot validation manuscript did not allow for retesting with an added question due to funding and time constraints. Future funding will seek to validate HELP survey questionnaire fit within identified themes as sample size increases within a similar disadvantaged chronic pain population. Corresponding validated PROMIS and DASS survey results also collected as part of the HELP study will be analyzed and compared with the HELP survey results to determine a pattern as sample size increases. The future goal is utilization of the HELP survey instrument for use in socially disadvantaged pain clinic populations to improve pain management assessment.

\section{Ethics Approval and Consent to Participate}

The University of Florida Institutional Review Board approved the conduct of this study. All participants consented to participate in research. All participants were informed about the purpose of the study, in accordance with the Declaration of Helsinki.

\section{Consent for Publication: Not Applicable}

Availability of data and materials: The data that support the findings of this study conducted at the University of Florida are not publicly available. Pertinent data are summarized with the publication.

\section{Acknowledgments}

The authors would like to express their appreciation to the participants and research associates who made it possible to complete this research project.

\section{Funding}

Research reported in this publication was supported by the University of Florida Clinical and Translational Science Institute, which is supported in part by the NIH National Center for Advancing Translational Sciences under award number UL1TR001427. The content is solely the responsibility of the authors and does not necessarily represent the official views of the National Institutes of Health. Also, research was supported by a grant from the Foundation for PM\&R.

\section{Disclosure}

The authors report no conflicts of interest in this work. 


\section{References}

1. Pitcher MH, Von Korff M, Bushnell MC, Porter L. Prevalence and profile of high-impact chronic pain in the United States. J Pain. 2019;20 (2):146-160. doi:10.1016/j.jpain.2018.07.006

2. Dahlhamer J, Lucas J, Zelaya C, et al. Prevalence of chronic pain and high-impact chronic pain among adults — United States, 2016. MMWR Morb Mortal Wkly Rep. 2018;67:1001-1006. doi:10.15585/mmwr.mm6736a2

3. Gatchel RJ, Peng YB, Peters ML, Fuchs PN, Turk DC. The biopsychosocial approach to chronic pain: scientific advances and future directions. Psychol Bull. 2007;133:581-624. doi:10.1037/0033-2909.133.4.581

4. Center for Disease Control and Prevention. "Health disparities"; 2018. Available from: https://www.cdc.gov/healthyyouth/disparities/index.htm. Accessed April 30, 2019.

5. Merkin SS, Basurto-Dávila R, Karlamangla A, et al. Neighborhoods and cumulative biological risk profiles by race/ethnicity in a national sample of U.S. adults: NHANES III. Ann Epidemiol. 2009;19(3):194-201. doi:10.1016/j.annepidem.2008.12.006

6. Karran EL, Grant AR, Moseley GL. Low back pain and the social determinants of health: a systematic review and narrative synthesis. Pain. 2020;161(11):2476-2493. doi:10.1097/j.pain.0000000000001944

7. Edwards RR, Dworkin RH, Sullivan MD, Turk DC, Wasan AD. The role of psychosocial processes in the development and maintenance of chronic pain. J Pain. 2016;17(9 Suppl):T70-92. doi:10.1016/j.jpain.2016.01.001

8. Artiga S, Hinton E. Beyond health care: the role of social determinants in promoting health and health equity; 2018. Available from: https://www. kff.org/disparities-policy/issue-brief/beyond-heath-care-the-role-of-social-determinants-in-promoting-health-and-health-equity/. Accessed March 2, 2021.

9. Hardman R, Lawn S, Tsourtos G. Pain self-management: easier said than done? Factors associated with early dropout from pain self-management in a rural primary care population. Pain Med. 2018. doi:10.1093/pm/pny167

10. Sullivan MJL, Thorn B, Keefe FJ, Martin M, Bradley LA, Lefebvre JC. Theoretical perspectives on the relation between catastrophizing and pain. Clin J Pain. 2001;17:52-64. doi:10.1097/00002508-200103000-00008

11. Michael JLS. The Pain Catastrophizing Scale User Manual. Departments of Psychology, Medicine, and Neurology. School of Physical and Occupational Therapy. Montreal, Quebec: McGill University; 1995. H3A 1B1. e-mail: michael.sullivan@mcgill.ca. Copyright 1995, 2001, 2004, 2006, 2009.

12. Wijma AJ, van Wilgen CP, Meeus M, Nijs J. Clinical biopsychosocial physiotherapy assessment of patients with chronic pain: the first step in pain neuroscience education. Physiother Theory Pract. 2016;32(5):368-384. doi:10.1080/09593985.2016.1194651

13. Hibbard JH, Stockard J, Mahoney ER, Tusler M. Development of the Patient Activation Measure (PAM): conceptualizing and measuring activation in patients and consumers. Health Services Res. 2004;39(4):1005-1026.

14. Canty-Mitchell J, Zimet GD. Psychometric properties of the multidimensional scale of perceived social support in urban adolescents. Am J Community Psychol. 2000;28:391-400. doi:10.1023/A:1005109522457

15. Zimet GD, Dahlem NW, Zimet SG, Farley GK. The multidimensional scale of perceived social support. J Pers Assess. 1988;52:30-41. doi:10.1207/s15327752jpa5201_2

16. Zimet GD, Powell SS, Farley GK, Werkman S, Berkoff KA. Psychometric characteristics of the multidimensional scale of perceived social support. J Pers Assess. 1990;55:610-617.

17. Jung D, Kind A, Robert S, Buckingham W, DuGoff E. Linking neighborhood context and health in community-dwelling older adults in the medicare advantage program. J Am Geriatr Soc. 2018;66(6):1158-1164. doi:10.1111/jgs.15366

18. Health Measures. "PROMIS" (healthmeasures.net). Available from: https://www.healthmeasures.net/index.php?option=com_content\&view=cate gory\&layout=blog\&id=147\&Itemid=806. Accessed March 12, 2021.

19. StataCorp. Stata Statistical Software: Release 16. College Station, TX: StataCorp LLC; 2019.

20. Singh GK. Area deprivation and widening inequalities in US mortality, 1969-1998. Am J Public Health. 2003;93(7):1137-1143. doi:10.2105/ AJPH.93.7.1137

21. Kind AJH, Jencks S, Brock J, et al. Neighborhood socioeconomic disadvantage and 30-day rehospitalizations: an analysis of Medicare data. Ann Intern Med. 2014;161(11):765-774. doi:10.7326/M13-2946

22. Mundfrom DJ, Shaw DG, Ke TL. Minimum sample size recommendations for conducting factor analyses. Int J Test. 2005;5(2):159-168. doi:10.1207/s15327574ijt0502_4

23. Preacher KJ, MacCallum RC. Exploratory factor analysis in behavior genetics research: factor recovery with small sample sizes. Behav Genet. 2002;32(2):153-161. doi:10.1023/A:1015210025234

24. de Winter JCF, Dodou D, Wieringa PA. Exploratory factor analysis with small sample sizes. Multivariate Behav Res. 2009;44(2):147-181. doi:10.1080/00273170902794206

25. Harris PA, Taylor R, Thielke R, Payne J, Gonzalez N, Conde JG. Research electronic data capture (REDCap) - a metadata-driven methodology and workflow process for providing translational research informatics support. J Biomed Inform. 2009;42(2):377-381. doi:10.1016/j.jbi.2008.08.010

26. Harris PA, Taylor R, Minor BL, et al.; REDCap Consortium. The REDCap consortium: building an international community of software partners. J Biomed Inform. 2019;95:103208. doi:10.1016/j.jbi.2019.1032

Journal of Pain Research

Dovepress

\section{Publish your work in this journal}

The Journal of Pain Research is an international, peer reviewed, open access, online journal that welcomes laboratory and clinical findings in the fields of pain research and the prevention and management of pain. Original research, reviews, symposium reports, hypothesis formation and commentaries are all considered for publication. The manuscript management system is completely online and includes a very quick and fair peer-review system, which is all easy to use. Visit http://www.dovepress.com/testimonials.php to read real quotes from published authors.

Submit your manuscript here: https://www.dovepress.com/journal-of-pain-research-journal 